\title{
Understanding the role of MAM molecular weight in the production of PMMA/MAM nanocellular polymers
}

\author{
Victoria Bernardo ${ }^{\mathrm{a}, *}$, Judith Martin-de Leon ${ }^{\mathrm{a}}$, Ester Laguna-Gutierrez ${ }^{\mathrm{a}}$, Tiziano Catelani ${ }^{\mathrm{b}}$, \\ Javier Pinto ${ }^{\mathrm{b}}$, Athanassia Athanassiou ${ }^{\mathrm{b}}$, Miguel Angel Rodriguez-Perez ${ }^{\mathrm{a}}$ \\ a Cellular Materials Laboratory (CellMat), Condensed Matter Physics Department, University of Valladolid, Valladolid, Spain \\ ${ }^{\mathrm{b}}$ Nanophysics, Istituto Italiano di Tecnologia (IIT), Genova, Italy
}

H I G H L I G H T S

- Nanocellular polymers based on PMMA/MAM blends are produced.

- Nanostructuration of the blends depends on MAM molecular weight.

- Then, MAM molecular weight can used as a tool to control the cellular structure.

\section{A R T I C L E I N F O}

\section{Keywords:}

Nanocellular polymer

Gas dissolution foaming

Nanostructuration

\begin{abstract}
A B S T R A C T
Nanostructured polymer blends with CO2-philic domains can be used to produce nanocellular materials with controlled nucleation. It is well known that this nanostructuration can be induced by the addition of a block copolymer poly(methyl methacrylate)-poly(butyl acrylate)-poly(methyl methacrylate) (MAM) to a poly(methyl methacrylate) (PMMA) matrix. However, the effect of the block copolymer molecular weight on the production of nanocellular materials is still unknown. In this work, this effect is analysed by using three types of MAM triblock copolymers with different molecular weights, and a fixed blend ratio of $90 \mathrm{wt} \%$ PMMA and $10 \mathrm{wt} \%$ of MAM. Blends were produced by extrusion. As a result of the extrusion process, a non-equilibrium nanostructuration takes place in the blends, and the micelle density increases as MAM molecular weight increases. Micelle formation is proposed to occur as result of two mechanisms: dispersion, controlled by the extrusion parameters and the relative viscosities of the polymers, and self-assembly of MAM molecules in the dispersed domains. On the other hand, in the nanocellular materials produced with these blends, cell size decreases from 200 to $120 \mathrm{~nm}$ as MAM molecular weight increases. Cell growth is suggested to be controlled by the intermicelle distance and limited by the cell wall thickness. Furthermore, a theoretical explanation of the mechanisms underlying the limited expansion of PMMA/MAM systems is proposed and discussed.
\end{abstract}

\section{Introduction}

The study of nanocellular polymers is an interesting topic in the frontier of cellular materials science. These materials are characterised by cell sizes in the range of tens to hundreds of nanometres. They have been recently proved to present a unique combination of properties, such as very low thermal conductivities together with improved mechanical properties, compared to conventional cellular polymers [1-6]. The criteria to determine the maximum cell size of such materials should be related to the effects associated with the change of scale to the nanometric range, so it may vary among properties. For instance, thermal conductivity starts to decrease significantly thanks to the
Knudsen effect from cell sizes of $500 \mathrm{~nm}$ [1,2], whereas for obtaining semi-transparent nanocellular polymers cell sizes as low as $50 \mathrm{~nm}$ are needed $[7,8]$. Therefore, nanocellular polymers with cell sizes below $500 \mathrm{~nm}$ could be used as highly efficient thermal insulator materials, whereas those with cell sizes of $50 \mathrm{~nm}$ could be employed in the production of semi-transparent and super insulator windows. In addition to these applications, and due to their nanometric cell size, nanocellular polymers can also be employed in some specific applications in which other cellular materials cannot be used; for instance, in membranes for micro and ultrafiltration applications or in catalysis and sensors [9-11].

However, the production of these materials is still a challenging task. The fabrication of nanocellular polymers requires specific

\footnotetext{
* Corresponding author.

E-mail address: vbernardo@fmc.uva.es (V. Bernardo).
} 
production routes able to produce and stabilise cells in the nanoscale. Among the diverse techniques employed for this purpose [1,12,13], foaming methods allow producing large samples without the use of organic solvents. In particular, $\mathrm{CO}_{2}$ gas dissolution foaming has been proved to be suitable for the production of bulk nanocellular polymers using different matrices, such as poly(methyl methacrylate) (PMMA) [7,14-16], polycarbonate (PC) [17], polysulfone (PSU) [18], polyphenylsulfone [19,20], or polyetherimide [21-23].

In particular, to produce nanocellular materials based on PMMA using the gas dissolution foaming method, two approaches have been followed based on homogeneous or heterogeneous nucleation. According to the nucleation theories for homogeneous nucleation [24], nucleation ratio in a pure polymer can be increased by maximising $\mathrm{CO}_{2}$ solubility using extreme processing conditions, a strategy followed in all the previously mentioned examples [7,14-16]. Otherwise, the nucleation can be enhanced by taking advantage of the heterogeneous nucleation mechanism. When adding an appropriate second phase to a pure polymer, the interfaces between the matrix and the second phase act as preferable nucleation sites, that is, the Gibbs energy barrier, which should be overcome to form a nucleus, is lower when this second phase is added [24]. To produce nanocellular polymers with this approach, nanoparticles [25-27] or block copolymer micelles [10,28-30] can be used as the second phase. In particular, block copolymer spherical micelles with $\mathrm{CO}_{2}$-philic domains gather all the qualities required to act as ideal nucleants: the nucleation is favourable in the micelles, they present uniform size and surface properties, they are easily dispersible, and the number of micelles formed is usually large [31].

The first successful attempts to produce nanocellular polymers using this approach were those of Yokoyama and coworkers [32,33] with solvent-cast films. Bulk nanocellular PMMA using a tri-block copolymer poly(methyl methacrylate)-poly(butyl acrylate)-poly(methyl methacrylate) (MAM) was produced for the first time by Reglero et al. [34]. They used a MAM with a $30 \%$ of the poly(butyl acrylate) (PBA) phase, with a molecular weight of $70 \mathrm{~kg} / \mathrm{mol}$ in that block and $90 \mathrm{~kg} / \mathrm{mol}$ in the PMMA blocks. Working with a MAM content of $10 \mathrm{wt} \%$ they were able to obtain cell sizes around $200 \mathrm{~nm}$ and relative densities of 0.4 . Pinto et al. [10,29,30] worked with blends of PMMA and MAM with different MAM contents and under several processing conditions. In their work, the MAM block copolymer used presented at $36 \mathrm{wt} \%$ of PBA and an average molecular weight of $180 \mathrm{~kg} / \mathrm{mol}$. They showed that nucleation actually took place in the micelles [29] and that the cellular structure was controlled by the nanostructuration. Cell sizes in the range $150-200 \mathrm{~nm}$ and relative densities of $0.4-0.6$ were obtained in these works. Forest and coworkers [28] analysed the effect of changing the copolymer content in the structure of PMMA/MAM-based nanocellular polymers, founding that higher copolymer contents (up to $20 \mathrm{wt} \%$ ) led to larger cell nucleation densities. They also analysed the effect of the PMMA viscoelastic behaviour in PMMA/MAM blends, by using two PMMA with different molecular weights [35]. They found that the viscoelastic behaviour of the PMMA matrix conditioned the cell growth mechanisms and thus, the density of the final material. In the works of Forest et al. [28,35], MAM with a 55\% of PBA block was used. The glass transition of the PBA phase was found at $-46^{\circ} \mathrm{C}$ and the molecular weight of the copolymer was not specified.

In the aforementioned literature, the effect of the copolymer content on the morphology of the blends and thus, on the cellular structure of these materials, has been widely analysed. The effect of the MAM chemistry on the nanostructuration under equilibrium conditions and the mechanical performance of solid PMMA/MAM blends has also been studied [36-39]. However, there is a lack of knowledge about the influence of the molecular weight of the copolymer on the nanostructuration when the blends are produced by extrusion, and also on the resultant nanocellular structure. Therefore, this work aims to identify the role of the block copolymer molecular weight in the production of nanocellular polymers. For this purpose, three grades of MAM tri-block copolymers will be used. In particular, it is the first time that the particular MAM grades of this work, with PBA ratios of $48-54 \%$ and glass transition temperatures of the PBA phase ranging -40 to $-20^{\circ} \mathrm{C}$, are used for producing nanocellular polymers. First, the influence of the MAM molecular weight on the nanostructuration of solid blends obtained by extrusion containing $90 \mathrm{wt} \%$ PMMA and $10 \mathrm{wt} \%$ of each MAM will be studied. Then, these solid blends will be employed as precursors to be foamed using a two-step gas dissolution foaming method with the goal of analysing the influence of the block copolymer molecular weight on the resultant cellular structure. The results show that the MAM molecular weight has a significant influence on the nanostructuration of the solid blends. In addition, it was proved that the nanostructuration controls the cell growth and stabilisation. Therefore, MAM molecular weight was demonstrated to be a critical processing parameter in the production of PMMA/MAM nanocellular materials.

\section{Experimental}

\subsection{Materials}

PMMA V 825T was kindly supplied by ALTUGLAS ${ }^{\circ}$ International in the form of pellets. PMMA $\left(\mathrm{M}_{\mathrm{n}}=43 \mathrm{~kg} / \mathrm{mol}, \mathrm{M}_{\mathrm{w}}=83 \mathrm{~kg} / \mathrm{mol}\right)$ with a melt flow index (MFI) of $1.8 \mathrm{~g} / 10 \mathrm{~min}$ (measured at $230{ }^{\circ} \mathrm{C}$ and $2.16 \mathrm{~kg}$ ), a density ( $\rho$ ) of $1.19 \mathrm{~g} / \mathrm{cm}^{3}$ and a glass transition temperature $\left(\mathrm{T}_{\mathrm{g}}\right.$ ) of $114.5^{\circ} \mathrm{C}$, measured by DSC.

MAM block copolymers were kindly supplied by Arkema Company (France). Three MAM copolymers with different molecular weights were used in this study. The three MAM present roughly a $48-54 \mathrm{wt} \%$ of the soft block, poly(butyl acrylate) (PBA), according to the data provided by Arkema and confirmed with NMR (Table 1, see Supplementary information for more details about the NMR). Commercial names of these copolymers are Nanostrength M51 (low molecular weight), M52 (medium molecular weight) and M53 (high molecular weight). Table 1 summarises the main characteristics of these copolymers. MFI was measured at $160^{\circ} \mathrm{C}$ and $10 \mathrm{~kg}$ and molecular weight was determined using GPC measurements. PBA fraction was determined from NMR measurements. $\mathrm{T}_{g}$ of the PBA phase was determined by DSC.

Further characterization of the block copolymers (molecular weight distributions and NMR measurements) can be found in the Supplementary Information.

Finally, medical grade carbon dioxide $\left(\mathrm{CO}_{2}\right)$ (99.9\% purity) was used as blowing agent for the gas dissolution foaming experiments.

\subsection{Solid blends production}

PMMA/MAM blends with a $10 \mathrm{wt} \%$ of MAM were compounded using a twin-screw extruder model COLLIN TEACH-LINE ZK 25T, with $\mathrm{L} / \mathrm{D}$ of 24 and screw diameter of $25 \mathrm{~mm}$. All materials were dried under vacuum at $50{ }^{\circ} \mathrm{C}$ during $12 \mathrm{~h}$ prior to compounding. The temperature profile set on the extruder varied from $160^{\circ} \mathrm{C}$ to $200^{\circ} \mathrm{C}$ (in the die), increasing in intervals of $10^{\circ} \mathrm{C}$. The screw speed was equal to $40 \mathrm{rpm}$. The produced blends were cooled in a water bath and pelletized. After a drying of $2 \mathrm{~h}$ in a vacuum oven at $50{ }^{\circ} \mathrm{C}$, the material was extruded

Table 1

Characteristics of the MAM block copolymers used in this work.

\begin{tabular}{lllllll}
\hline ID & Description & $\begin{array}{l}\mathrm{M}_{\mathrm{n}} \\
(\mathrm{kg} / \\
\mathrm{mol})\end{array}$ & $\begin{array}{l}\mathrm{M}_{\mathrm{w}} \\
(\mathrm{kg} / \\
\mathrm{mol})\end{array}$ & MFI (g/10 min) & $\mathrm{T}_{\mathrm{g}, \mathrm{PBA}}\left({ }^{\circ} \mathrm{C}\right)$ & $\begin{array}{l}\text { PBA } \\
(\mathrm{wt} \%)\end{array}$ \\
\hline $\mathrm{L}$ & $\begin{array}{l}\text { Low molecular } \\
\text { weight } \\
\text { Medium } \\
\text { molecular }\end{array}$ & 25 & 46 & $84 \pm 9$ & -26.2 & 48 \\
$\mathrm{H}$ & 44 & 75 & $4 \pm 1$ & -34.9 & 52 \\
$\mathrm{H}$ & $\begin{array}{l}\text { weight } \\
\text { High molecular } \\
\text { weight }\end{array}$ & 82 & 128 & $0.208 \pm 0.003$ & -39.8 & 54 \\
\hline
\end{tabular}


again under the same conditions, with the aim of homogeneously mixing the two components. After this process, homogeneous and transparent blends were obtained. Blends will be called from now on as 90/10_L, 90/10_M and 90/10_H (that is, $90 \mathrm{wt} \%$ of PMMA and $10 \mathrm{wt} \%$ of MAM with low (L), medium (M) or high (H) molecular weight).

Solid precursors of the blends with different geometries were prepared by compression moulding using a hot plate press provided by Remtex. All materials were dried under vacuum at $50^{\circ} \mathrm{C}$ during $12 \mathrm{~h}$ before processing. The temperature of the press was fixed at $250{ }^{\circ} \mathrm{C}$. The materials were first softened without pressure for $8.5 \mathrm{~min}$, and then, they were compacted under a constant pressure of 1.7 MPa for another minute. Finally, the samples were cooled down to room temperature under the same pressure. Solid prisms of $155 \times 75 \times 4 \mathrm{~mm}^{3}$ were produced and samples of $20 \times 10 \times 4 \mathrm{~mm}^{3}$ were cut from the solid prisms and used in the foaming experiments. In addition, cylindrical samples for the shear rheological measurements with a thickness of $2 \mathrm{~mm}$ and a diameter of $25 \mathrm{~mm}$ were prepared using the same press and the same conditions.

Neat PMMA was processed under the same conditions (both by extrusion and compression moulding) for the sake of comparison.

\subsection{Gas dissolution foaming experiments}

Foaming experiments were performed in a high-pressure vessel (model PARR 4681) provided by Parr Instruments Company with a capacity of 1 litre, capable of operating at a maximum temperature of $350^{\circ} \mathrm{C}$ and a maximum pressure of $41 \mathrm{MPa}$. An accurate pressure pump controller (model SFT-10) provided by Supercritical Fluid Technologies Inc. controls automatically the pressure to keep the desired value. The vessel is equipped with a clamp heater of $1200 \mathrm{~W}$, and its temperature is controlled via a CAL 3300 temperature controller. With this set up foaming experiments were performed using a two-step foaming process [40]. Samples were firstly introduced in the pressure vessel under a particular pressure for the saturation stage. After saturation, the pressure was abruptly released at a pressure drop rate of $15 \mathrm{MPa} / \mathrm{s}$. Then samples were removed from the pressure vessel and immersed in a thermal bath at the desired foaming temperature. The time between the release of pressure and the immersion of samples in the baths was $3.5 \mathrm{~min}$.

The saturation temperature was fixed at $25^{\circ} \mathrm{C}$, the saturation pressure was equal to $10 \mathrm{MPa}$, and the saturation time was $20 \mathrm{~h}$, as this time is enough to ensure that the PMMA samples will be saturated at these conditions [29]. Foaming was carried out in a water bath at $80^{\circ} \mathrm{C}$ during $1.5 \mathrm{~min}$. It is important to remark that under these saturation conditions $\left(25^{\circ} \mathrm{C}\right.$ and $10 \mathrm{MPa}$ ) the effective glass transition temperature of PMMA after the gas absorption is below room temperature [29], so samples start to expand immediately after the release of pressure. Nevertheless, this expansion is clearly smaller than that taking place when the samples are introduced in the thermal bath.

\subsection{Characterization}

\subsubsection{Nanostructuration of the blends}

Nanostructuration of the solid PMMA/MAM precursors was analysed using transmission electron microscopy (TEM). For this purpose, each sample was cut in ultrathin slices (with a thickness of approximately 80-90 nm) using a Leica EM UC6 Ultramicrotome. Because of the soft behaviour of the polymer, it was necessary to trim and cut all the samples in cryogenic conditions, cooling down the environment and the sample holder at least at $-60^{\circ} \mathrm{C}$, using a specific cryo-system Leica EM FC6 and a specific diamond knife for low-temperature cuts. Slices were collected and laid down onto a 200 mesh formvar/carbon-coated copper TEM grids.

Transmission electron microscopy (TEM) images were collected with a Jeol JEM 1011 (Jeol, Japan) electron microscope (Electron Microscopy Lab. - Nanochemistry Dept., Istituto Italiano di Tecnologia), operating at an acceleration voltage of $100 \mathrm{kV}$, and recorded with an 11 Mp fiber optical charge-coupled device (CCD) camera (Gatan Orius SC1000).

TEM images were used to quantify the nanostructuration found in the solid blends. Micelle size $\left(\phi_{m}\right)$ was measured using the software ImageJ/FIJI [41,42]. More than 100 micelles of different areas were considered for the analysis. The standard deviation (SD) of the micelle size distribution and the normalised parameter $\mathrm{SD} / \phi_{m}$ were calculated as an indicator of the homogeneity of the micelle size distribution. The volumetric micelle density $\left(n_{\text {mic }}\right)$ was calculated by dividing the number of micelles in a TEM image by the volume (area of the image times the thickness of the sample (around $80 \mathrm{~nm}$ )). In addition, the intermicelle distance was measured using a Delaunay-Voronoi diagram in Image J/ FIJI [42].

From the micelle density $\left(n_{m i c}\right.$ ), the aggregation number $N_{c}$ (number of copolymer molecules per micelle) was estimated theoretically using equation (1) [31], where $w$ is the amount of copolymer, $N_{a v}$ is the Avogadro's number, $\rho$ is the density of the blend, and $M_{n}$ is the molecular weight of the copolymer.

$N_{c}=\frac{w N_{a v} \rho}{M_{n} n_{\text {mic }}}$

\subsubsection{Rheological behaviour}

Rheological behaviour of the pure PMMA and the PMMA/MAM blends was investigated using a stress-controlled rheometer, AR 2000 EX from TA Instruments. Shear rheology measurements were performed at a temperature equal to $230{ }^{\circ} \mathrm{C}$ under a nitrogen atmosphere using a parallel plates geometry of $25 \mathrm{~mm}$ in diameter and a fixed gap of $1 \mathrm{~mm}$. Dynamic-mechanical experiments over an angular frequency range of $0.01<\omega<100 \mathrm{rad} / \mathrm{s}$ were performed for all the blends and the pure polymer. A strain of $4 \%$ for the pure PMMA and $6 \%$ for the PMMA/ MAM blends, both within the linear viscoelastic response of the different materials, was used. From these measurements three magnitudes were analysed: the dynamic shear viscosity $\left(\eta^{*}\right)$, the storage modulus $\left(G^{\prime}\right)$ and the loss modulus $\left(G^{\prime \prime}\right)$.

\subsubsection{Density}

The density of the solid samples was measured with a gas pycnometer (model AccuPyc II 1340, Micromeritics). The density of the corresponding cellular materials was determined with the water-displacement method based on Archimedes' principle. A density determination kit for an AT261 Mettler-Toledo balance has been used for this purpose. The solid skin of the foamed samples was removed out with a polisher (model LaboPOl2-LaboForce3, Struers) before measuring their densities. Relative density $\left(\rho_{\mathrm{r}}\right)$ was calculated as the ratio between the cellular material density $\left(\rho_{\mathrm{f}}\right)$ and the density of the solid polymer blend $\left(\rho_{s}\right)$.

\subsection{4. $\mathrm{CO}_{2}$ uptake}

The amount of gas uptake was calculated as the percentage of weight increment of the sample due to the $\mathrm{CO}_{2}$ sorption. The initial mass was measured after drying the samples and before being placed in the pressure vessel and the final weight was evaluated by weighting the samples immediately after being removed from the pressure vessel. The time between the depressurisation and the weight measurement was around $2 \mathrm{~min}$. During this time some gas was lost due to gas diffusion out of the sample. Thus, these measurements are only an estimation of the solubility, and therefore the values obtained were only used for comparison between the different samples.

\subsubsection{Cellular structure}

The cellular structure of the samples was analysed using an ESEM, Environmental Scanning Electron Microscope (Quanta 200 FEG). With the aim of maintaining the cellular structure for the microscopic visualisation, samples were cooled in liquid nitrogen, fractured and 
finally coated with gold using a sputter coater (model SCD 005, Balzers Union). Various parameters were measured in order to obtain a complete analysis of the cellular structure. A tool based on the software ImageJ/FIJI [41,42] was used to quantify the structural parameters. Firstly, the average cell size $(\phi)$, the cell size distribution and the standard deviation coefficient of the cell size distribution (SD) were obtained. The parameter $\mathrm{SD} / \phi$ (normalised standard deviation coefficient) was calculated as an indicator of the homogeneity of the cellular structure. This parameter is used for comparison between materials with a different cell size. Cell density $\left(N_{v}\right)$ and cell nucleation density $\left(N_{0}\right)$ were determined using Kumar's theoretical approximation [43] according to equations (2) and (3), respectively, where $n$ is the number of cells in the image and $A$ is the area of the image. More than 200 cells of different areas of each cellular material were analysed.

$N_{v}=\left[\frac{n}{A}\right]^{3 / 2}$

$N_{0}=\frac{N_{v}}{\rho_{r}}$

Cell wall thickness of the cellular materials was measured directly from the micrographs. More than fifty cell walls were measured per material.

\section{Results and discussion}

\subsection{Nanostructuration of the blends}

Fig. 1 shows the TEM images of the solid PMMA/MAM blends. The TEM micrographs reveal the existence of a nanostructuration in these materials. As seen in the images, block copolymer self-assemble forming nanometric spherical micelles. Note that these nanostructures are a consequence of an extrusion process, and thus they can be considered as non-equilibrium structures.

The influence of MAM copolymer molecular weight on the nanostructuration can be appreciated in Fig. 1; the higher the molecular weight, the greater the number of micelles, for the same area. This first impression was later on confirmed by the analysis of the micelle density (Table 2). It is important to remark that this analysis is based on the interfaces between the micelle and the matrix detected by TEM, and no staining was used to reveal the block copolymer. An increase in the micelle density is detected when the MAM molecular weight increases. In fact, the blend containing the copolymer with the lowest molecular weight, 90/10_L, shows a micelle density almost four times smaller than that of the blend 90/10_H. This is an important result which could induce significant differences in the cellular structure when these materials are used for foaming applications.

Moreover, the micelle size looks smaller for higher MAM molecular weights (Fig. 1). The average apparent size of the micelles varies from
Table 2

Nanostructure characteristic of PMMA/MAM 90/10 solid blends precursors.

\begin{tabular}{lllll}
\hline Sample ID & $\begin{array}{l}\text { Micelle density } \\
\left(\text { micelles } / \mathrm{cm}^{3}\right)\end{array}$ & $\begin{array}{l}\text { Micelle size } \\
(\mathrm{nm})\end{array}$ & $\frac{\mathrm{SD}}{\phi_{\boldsymbol{m}}}$ & $\begin{array}{l}\text { Aggregation } \\
\text { number }\end{array}$ \\
\hline 90/10_L & $(2.1 \pm 0.0) \cdot 10^{14}$ & 68 & 0.37 & $\begin{array}{l}13400 \\
\text { 90/10_M }\end{array}$ \\
$(7.3 \pm 0.4) \cdot 10^{14}$ & 60 & 0.37 & 2200 \\
90/10_H & $(7.7 \pm 0.9) \cdot 10^{14}$ & 40 & 0.35 & 1100 \\
\hline
\end{tabular}

$40 \mathrm{~nm}$ for $90 / 10 \_H$ to $70 \mathrm{~nm}$ for $90 / 10 \_\mathrm{L}$ (Table 2). This is in agreement with the micelle density trends, as the three blends have a constant content of MAM. In conclusion, increasing MAM molecular weight leads to smaller micelles and higher micelle densities. On the other hand, micelle size distributions in the three blends are homogeneous and present similar homogeneities, as they show a similar value of the parameter $\mathrm{SD} / \phi_{m}$ (Table 2 ).

The differences among the three copolymers are too high to be related with the small differences found in the PBA content (Table 1). In addition, previous works show that micelle densities as high as $4 \cdot 10^{14}$ nuclei/ $\mathrm{cm}^{3}$ could be achieved in 90/10 PMMA/MAM blends with only a $36 \mathrm{wt} \%$ of PBA in the MAM phase [29], higher than that obtained with the blend 90/10_L that has a higher PBA content. Then, the variations found in the blends of this work should be related with the different molecular weights of the copolymers.

In order to understand the origin of the nanostructuration of the blends, we propose that it might be a consequence of two processes: the dispersion of the MAM in the PMMA during the extrusion process and the self-assembly of the MAM molecules to form the micelles. The first process is controlled by the relative viscosities of the PMMA and the MAM at the extrusion conditions. According to the model proposed by $\mathrm{Wu}$ [44], when a polymer of viscosity $\eta_{d}$ is dispersed in a matrix of viscosity $\eta_{m}$ (with $\eta_{m}>\eta_{d}$, according to the MFI data reported in section 2.1 ), the dispersed phase will form aggregates of size:

$d=\frac{\sigma \cdot 4}{\eta_{m}^{0.16} \dot{\gamma} \eta_{d}^{0.84}}$

Where $\sigma$ is the interphase surface tension and $\dot{\gamma}$ is the shear velocity of the extruder screws. According to this equation, for a fixed matrix, the size of the aggregates will decrease with increasing viscosity of the dispersed polymer. Since higher molecular weights are associated with higher viscosities (see Table 1), then the higher the MAM molecular weight, the smaller the aggregates or MAM-rich regions.

On the other hand, in the MAM-rich regions, molecules should selfassembly to create the micelles. For an equilibrium process, the maximum number of micelles $\left(n_{\max }\right)$ can be estimated theoretically [31] according to equation (4). Assuming constant aggregation number and copolymer content, this equation would predict that the number of micelles will depend inversely on the molecular weight. But during the extrusion process (non-equilibrium), the MAM is dispersed in regions

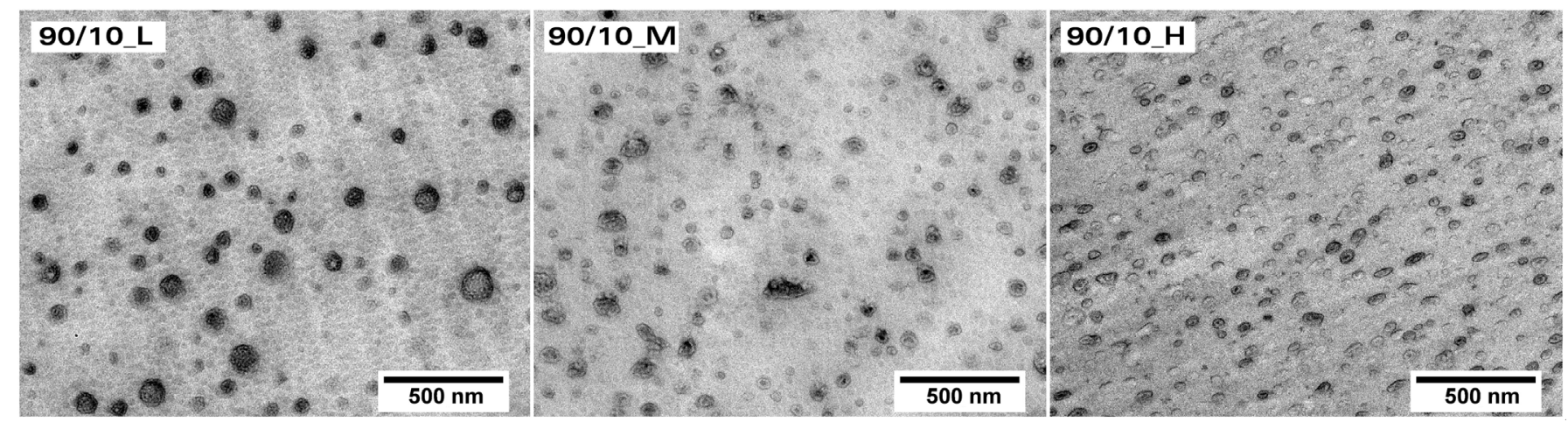

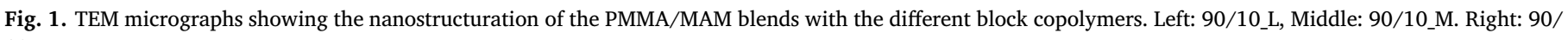
10_H. 
which are smaller for higher molecular weights. Then, it is plausible to assume that the number of molecules in each region will decrease with the increase of the molecular weight, as not only the regions are smaller but also the molecules occupy a higher volume. If the molecules in each MAM-rich region self-assembly in a micelle, then the number of molecules in a micelle (that is, the aggregation number) will be smaller for larger MAM molecular weights. This hypothesis is in agreement with equation (4) and the results of Table 2, in which the aggregation numbers were estimated. Aggregation numbers ranging 1100-13000 were calculated for these systems. These results are in agreement with the typical aggregation numbers found in the literature, which vary from 1000 to 10000 [45] to 40-400 [46].

Hence, the dispersion of the copolymer during the extrusion process is the key process controlling the nanostructuration of the blends. Therefore, by adjusting the extrusion parameters, the size of the MAMrich dispersed regions could be reduced, and thus the aggregation number decreased, yielding to higher micelle densities for the same amount of MAM. It is interesting to calculate the maximum micelle density achievable with these PMMA/MAM systems assuming a smaller aggregation number. For instance, for an aggregation number of 400, micelle densities as high as $5 \cdot 10^{15}$ micelles $/ \mathrm{cm}^{3}$ could be achieved. Therefore, there could be room for a further improvement of the nanostructure by adjusting the extrusion parameters. If the optimization of the extrusion process allows the dispersion of the MAM on small regions of about 400 molecules, it would be possible to increase the nucleation density in one order of magnitude.

\subsection{Rheological behaviour}

Fig. 2 shows the complex viscosity (a), the storage modulus (b) and the loss modulus (c) as a function of angular frequency for the pure PMMA and the for the blends containing $10 \%$ of the high, medium and low molecular weight MAMs. Fig. 2.a indicates that there is a relationship between the complex viscosity (obtained at low frequencies) and the copolymer molecular weight. The lower the MAM molecular weight, the lower the complex viscosity of the blend.

Moreover, these measurements also indicate that at low frequencies, in the terminal region, the shape of the complex viscosity and storage modulus curves depends on the polymer matrix. The pure PMMA follows the typical behaviour of a thermoplastic polymer. The storage modulus is proportional to the square of the frequency, $G^{\prime} \propto \omega^{2}$ and the loss modulus is proportional to the frequency, $G^{\prime \prime} \propto \omega$. Guided lines of these slopes have been added to Fig. $2 b$ and $2 c$ as reference. On the other hand, the complex viscosity reaches a Newtonian plateau. However, the PMMA/MAM blends do not follow this trend. Fig. 2 indicates that as the MAM molecular weight increases the Newtonian plateau is progressively replaced by a non-Newtonian power law (Fig. 2a) and the slope of the storage modulus is approaching zero (Fig. 2b). In particular, for the blend 90/10_H, the slope is as low as 0.4 . This behaviour could be ascribed to a percolation phenomenon produced by the fact of having an incompatible polymer blend, which was previously observed through TEM characterization (Fig. 1) [47,48]. An increase in the MAM molecular weight led to an increase of the micelle density (see Table 2) and hence, to a stronger interaction between the micelles, as they are closer. It has been reported for different polymer blends with rubber particles that the drastic increase of the complex viscosity in the terminal region and the appearance of a secondary plateau in the storage modulus curve, at low frequencies, is attributed to a network-type structure formed by the soft nodules $[28,47,48]$.

\subsection{Cellular structure}

Cellular materials were obtained from the solid PMMA and PMMA/ MAM blends at constant saturation $\left(10 \mathrm{MPa}\right.$ and $\left.25^{\circ} \mathrm{C}\right)$ and foaming $\left(80^{\circ} \mathrm{C}\right.$ and $1.5 \mathrm{~min}$ ) conditions. The cellular structure of these materials was characterised to analyse the effect of the MAM copolymer
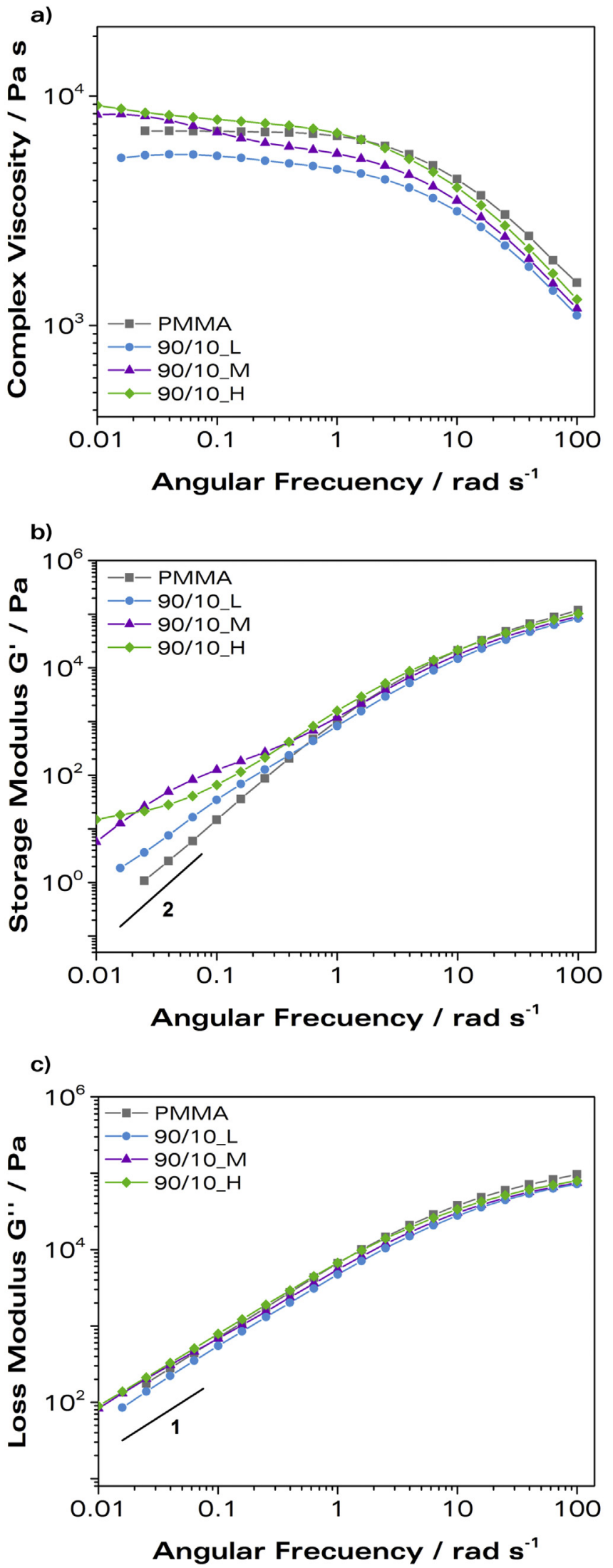

Fig. 2. a) Complex viscosity, b) storage modulus ( $\left.G^{\prime}\right)$ and c) loss modulus ( $\left.G^{\prime \prime}\right)$ of PMMA and PMMA/MAM blends as a function of the angular frequency at $230^{\circ} \mathrm{C}$. The slope of the typical behaviour of a typical thermoplastic polymer of both the storage modulus and the loss modulus in the terminal region is also shown in this figure. 
Table 3

Cellular structure characteristics of the samples produced at $10 \mathrm{MPa}$ of saturation pressure and $80^{\circ} \mathrm{C}$ of foaming temperature.

\begin{tabular}{|c|c|c|c|c|c|c|}
\hline Sample & $\begin{array}{l}\text { Gas } \\
\text { Uptake } \\
(w t \%)\end{array}$ & $\begin{array}{l}\text { Relative } \\
\text { Density }\end{array}$ & $\begin{array}{l}\text { Cell Nucleation } \\
\text { Density (nuclei/ } \\
\mathrm{cm}^{3} \text { ) }\end{array}$ & $\begin{array}{l}\text { Cell } \\
\text { Size } \\
(\mathrm{nm})\end{array}$ & $\frac{S D}{\phi}$ & $\begin{array}{l}\text { Cell Wall } \\
\text { Thickness } \\
(\mathrm{nm})\end{array}$ \\
\hline PMMA & 24.1 & 0.30 & $\begin{array}{l}(5.60 \pm 0.50) \\
10^{11}\end{array}$ & 1701 & 0.82 & $160 \pm 50$ \\
\hline 90/10_L & 25.5 & 0.37 & $\begin{array}{l}(2.51 \pm 0.70) \\
10^{14}\end{array}$ & 202 & 0.80 & $28 \pm 6$ \\
\hline 90/10_M & 25.4 & 0.49 & $\begin{array}{l}(4.48 \pm 0.00) \\
10^{14}\end{array}$ & 156 & 0.64 & $24 \pm 6$ \\
\hline 90/10_H & 25.6 & 0.57 & $\begin{array}{l}(8.74 \pm 0.30) \\
10^{14}\end{array}$ & 119 & 0.43 & $25 \pm 6$ \\
\hline
\end{tabular}

molecular weight on the foaming process. Table 3 summarises the structural parameters of these materials.

Under these conditions, pure PMMA absorbs a $24.1 \mathrm{wt} \%$ of $\mathrm{CO}_{2}$ (Table 3). Solubility measurements in the PMMA/MAM blends show that $\mathrm{CO}_{2}$ absorption increases with respect to the pure polymer up to a $25.5 \mathrm{wt} \%$, approximately. Literature data show that PBA homopolymer has a higher $\mathrm{CO}_{2}$ solubility than PMMA [49]; as a result, higher $\mathrm{CO}_{2}$ concentrations are measured in the blends containing MAM. Similar results were also found by Pinto and coworkers [10,29,30]. Moreover, these results also indicate that the MAM molecular weight is not affecting the blend solubility as no trend is observed by modifying this parameter.

Fig. 3 shows the cellular structure of the pure polymer and the different blends. Clear differences are found among these materials. Whereas the pure polymer presents a microcellular structure (Fig. 3a), the blends with MAM show a nanocellular structure (Fig. 3b, 4c and 3d). This different behaviour can be explained taking into account that the saturation pressure used (10 MPa) is not high enough to achieve a nanocellular structure in the pure PMMA. However, the nanostructure found in the PMMA/MAM blends supports their excellent performance as systems to produce nanocellular materials, without the need of using extremely high saturation pressures.

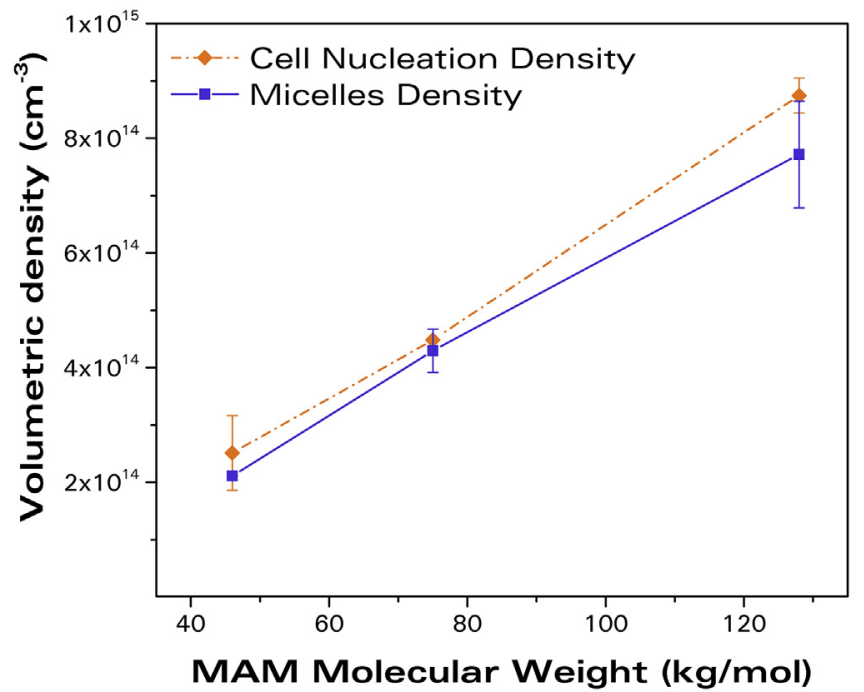

Fig. 4. Micelle density and cell nucleation density (at $80^{\circ} \mathrm{C}$ ) as a function of the MAM molecular weight.

At these conditions, the pure polymer shows a cell nucleation density of $5.6 \cdot 10^{11}$ nuclei $/ \mathrm{cm}^{3}$ (Table 3 ), while the PMMA/MAM blends have cell nucleation densities higher than $10^{14}$ nuclei $/ \mathrm{cm}^{3}$ (Table 3). In order to analyse the effect of the MAM molecular weight on nucleation, cell nucleation density was plotted as a function of the molecular weight and compared with the micelle density (Fig. 4). Both the cell nucleation density and the micelle density increase with block copolymer molecular weight. In addition, these nucleation densities are similar to the micelle densities found in the solid precursors (Fig. 4). These results support the already proved fact that the nanostructuration in the PMMA/MAM blends is controlling the cell nucleation density in the cellular material [29], that is, one micelle in the solid precursor contributes to the creation of one single cell in the cellular material. This result implies that no coalescence is taking place in these materials. Therefore, the molecular weight of the MAM can be used as a tool
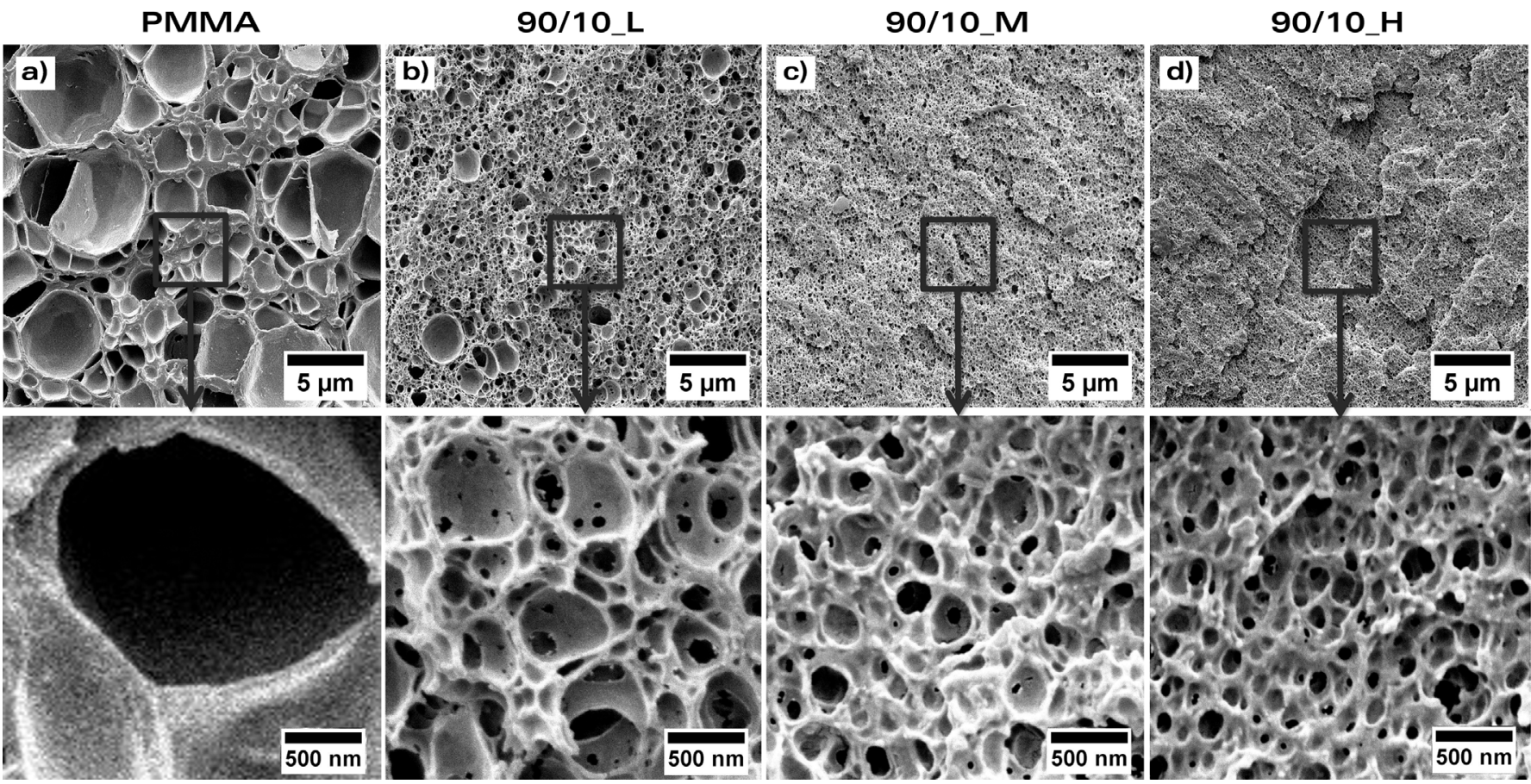

Fig. 3. SEM images of the samples produced at $10 \mathrm{MPa}$ of saturation pressure and $80^{\circ} \mathrm{C}$ of foaming temperature, a) PMMA, b) $90 / 10 \_\mathrm{L}$, c) $90 / 10 \_\mathrm{M}$ and d) $90 / 10 \_\mathrm{H}$. The second row corresponds to high-magnification images. 

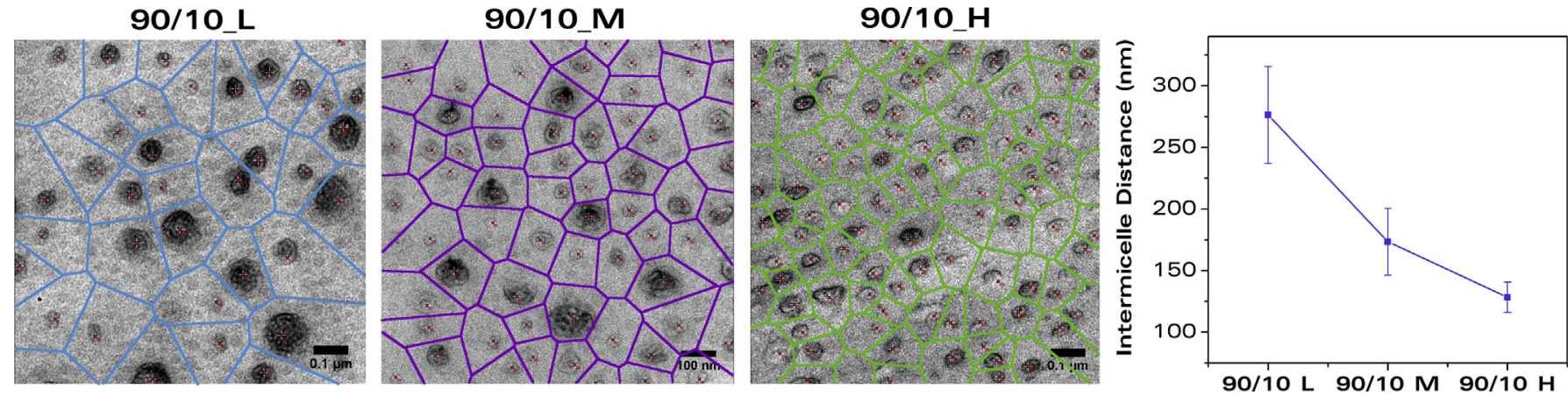

Fig. 5. Voronoi diagrams and results: average intermicelle distance and standard deviation.

to control firstly the micelles nanostructuration and then, the cell nucleation density. With the block copolymers used in this work, cell nucleation density can be varied in a factor of 4 (from $2 \cdot 10^{14}$ to $8 \cdot 10^{14}$ nuclei $/ \mathrm{cm}^{3}$ ) just by tuning the molecular weight of the block copolymer.

Regarding the cell size of the materials, it is observed that it decreases as MAM molecular weight increases (Table 3). In particular, a cell size of $200 \mathrm{~nm}$ is observed for 90/10_L, while 90/10_H presents a cell size of $120 \mathrm{~nm}$. This result can be explained taking into account that the higher the nucleation density, the more limited is the growing of the cells, yielding to smaller cell sizes. This can be precisely understood by observing the Voronoi diagrams of the micelle nanostructations on the solids (Fig. 5): the higher the number of micelles, the smaller the area of the tessellation polygons and the distance between the micelles (intermicelle distance), so the smaller the space available for growing. In fact, the intermicelle distances in the solid blends show a similar trend with the MAM molecular weight than the cell size of the cellular materials (see Table 3), supporting this idea.

In addition to the differences found in the cell size, it was detected that the homogeneity of the cellular structure (measured by the parameter $S D / \phi$ ) is also influenced by the MAM molecular weight. Table 3 shows that the pure polymer and the blend 90/10_L show a very heterogeneous cell size distribution $(S D / \phi$ higher than 0.8$)$, while the other two blends, 90/10_M and 90/10_H, present a better homogeneity (lower values of $S D / \phi$.) In Fig. 3b, which showed the cellular structure of the blend 90/10_L, the very heterogeneous cell size distribution of this material can be appreciated. This result can be related with the heterogeneous distribution of the distance between the micelles, shown in Fig. 6 (notice the standard deviation of the intermicelle distance is much higher in the blend 90/10_L). This heterogeneous dispersion of the micelles may cause that each micelle has a different space for growing, leading to a heterogeneous cellular structure.

Regarding the effect of the molecular weight on the relative density, an increase of this parameter is observed when the MAM molecular weight increases (Table 3). Besides, the relative density reached with the PMMA/MAM blends is higher than that of the pure polymer despite the largest $\mathrm{CO}_{2}$ uptake in the blends. This is a known limitation of the strategy of using block copolymers to produce nanocellular polymers. It is believed that nucleation takes place within the micelles [29] and hence, the nanodomains cannot grow enough to achieve large expansion ratios [5]. In this work, we proposed a theoretical explanation of this phenomenon by taking into account the cell wall thickness measured in these materials. It is observed that this parameter is constant (around $25 \mathrm{~nm}$ ) for the three cellular materials, independently of the MAM molecular weight (Table 3). So we hypothesised that the micelles grow until the polymer between them reaches a minimum limit of thickness. After this limit is achieved, no further expansion occurs. This is schematized in the first column of Fig. 6. The physical mechanism underlying this limitation may be related to the stretching of the polymer molecular chains in very thin cell walls. Once all the molecules are aligned no further stretching is allowed and confinement effect appears [6]. On the other hand, there may be a geometric limitation due to the size of the polymeric chains in the nanometric range [50,51]. Furthermore, once a very thin cell wall is reached, walls may fail, causing ruptures in the walls. Then, cellular structure becomes open cell and gas pressure is lost through the holes, preventing further expansion [7].

Our argument agrees with relevant literature results; for instance, in PMMA nanocellular polymers a cell wall thickness of around $25 \mathrm{~nm}$ was measured [7] and in PMMA/MAM system this value was around $30 \mathrm{~nm}$ [6]. Moreover, cell wall thickness in other works with PMMA and PMMA copolymers $[25,29,35]$ also varies in the range $25-30 \mathrm{~nm}$. Thus, it looks like cell wall thickness limitation is indeed a mechanism that should be taken into consideration to understand the formation of nanocellular polymers. Assuming that this is the mechanism that limits the expansion, we can explain the differences in relative density found for the different MAM molecular weights. We observed that the higher the MAM molecular weight, the higher the relative density of the cellular material. Higher MAM molecular weights imply larger number of micelles and therefore smaller distances among them. Thus more micelles have less space to grow before reaching this minimum cell wall thickness. As a result, higher micelle densities in the solid (higher MAM molecular weights) produce higher densities in the cellular material.

In an own previous work [7] we detected a cell wall thickness of around $25 \mathrm{~nm}$ for nanocellular polymers based on pure PMMA. However, in that work we proved that density could be further reduced by reducing the fraction of mass in the struts, obtaining relative densities as low as 0.24 . However, this is not observed in the PMMA/MAM-based materials. The explanation is schematized in Fig. 6. In a pure PMMA, the nuclei can grow into cells until they reach a minimum cell wall thickness. After that, the cells can further grow by reducing the struts thickness, becoming polygons. In a PMMA/MAM-based system, the growing mechanism is entirely different. Nucleation takes places within the micelle, and the micelle itself grows to form the cells. The existence of the micelles implies the presence of certain order between the MAM and PMMA molecules of the micelles and around them. Once the nucleation takes place and the cells start to grow, this molecular order plays a role on the expansion of the cells, promoting the preservation of the spherical shape (i.e., the change from spheres to polygons requires not only the stretching of the molecules, but also a disruption of this molecular order; whereas on an homogeneous PMMA matrix the molecules present a higher freedom allowing the adoption of polygon shapes). This theoretical explanation matches with the literature view of the limited cell packing of templated systems [5].

\section{Conclusions}

Nanocellular polymeric materials based on PMMA/MAM blends have been produced by means of a two-step gas dissolution foaming process. Three MAM copolymers were used with the aim of analysing the effect of the molecular weight of the block copolymer. Throughout the paper, it was shown that MAM molecular weight could be used as a 


\section{PMMA/MAM}

a)

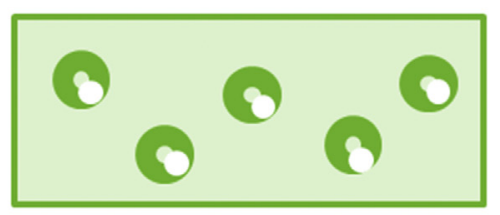

b)

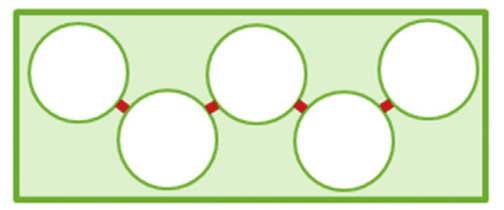

c)

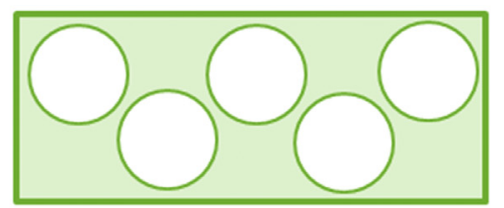

d)

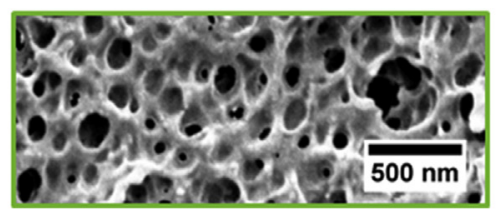

PMMA
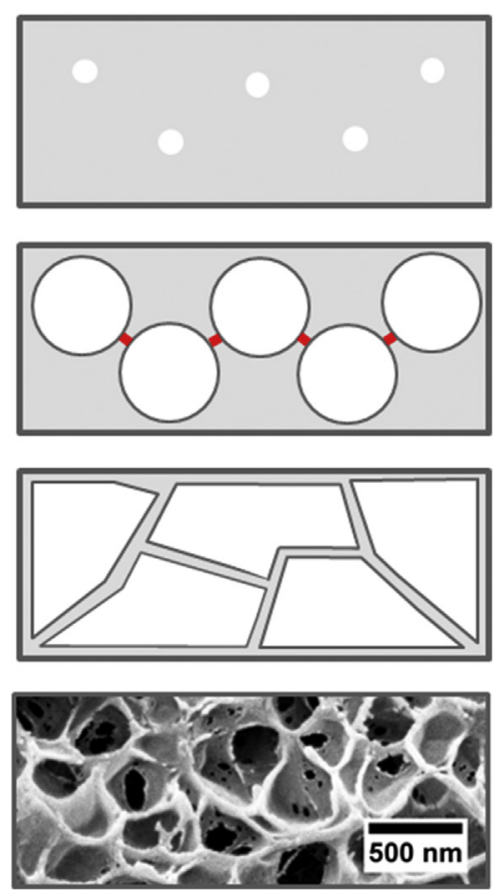

Fig. 6. Growing mechanisms in a PMMA/MAM blend and a pure PMMA: a) Nucleation in the micelles or the PMMA, b) growing until a minimum cell wall thickness is reached, c) stabilisation of the spherical cells in the PMMA/MAM system and further growth in the PMMA system by reducing the struts thickness and d) SEM images showing spherical cells in PMMA/MAM and polygonal cells in PMMA. tool to control the nanostructuration in PMMA/MAM blends, which in turn controls the cellular structure.

In particular, nanostructuration of the blends was studied by TEM image analysis. It was detected that after the extrusion process a nanostructuration appears in the PMMA/MAM solid blends. Note that these structures should be considered as non-equilibrium structures. The micelle density was found to increase as MAM molecular weight increases. To explain this result, two phenomena must be taken into consideration: the dispersion of the MAM during the extrusion process and the self-assembly of the MAM molecules. During the extrusion process, a MAM with higher viscosity (i.e., higher molecular weight) is dispersed in smaller domains. In these MAM-rich domains, self-assembly takes place, in such a way that the aggregation number is lower for higher molecular weights, leading to higher micelle densities. Therefore, extrusion process could be tuned to control or modify the nanostructuration of the blends.

Regarding the cellular materials, higher MAM molecular weights produce nanocellular materials with higher cell nucleation densities. In fact, micelle density and cell nucleation density are practically the same, so it was confirmed that nucleation happens within the micelles and each micelle produces a cell. Cell size decreases as MAM molecular weight increases. This is a result of the distance between the micelles. The intermicelle distance decreases as micelle density increases, so the micelles have less space to grow. The homogeneity of the cellular structure was proved to be directly related to the homogeneity of the intermicelle distance. In addition, it was detected that the relative density increases as MAM molecular weight increases. Once again, this result can be related to the growing of the cells. We proposed that cells can grow until a minimum cell wall thickness (of around $25 \mathrm{~nm}$ ) is reached. As this minimum thickness is reached sooner for higher MAM molecular weights (smaller intermicelle distance), higher densities are obtained. In addition, the mechanisms of growing in PMMA/MAM systems were discussed. We hypothesise that micelles could only grow spherically, this being the reason underneath the limited expansion that can be achieved with these systems.

\section{Acknowledgements}

Financial assistance from MINECO, FEDER, UE (MAT2015-69234R) and the Junta de Castile and Leon (VA011U16) are gratefully acknowledged. Financial support from Junta of Castile and Leon grant (J. Martín-de León) and FPU grant FPU14/02050 (V. Bernardo) from the Spanish Ministry of Education is gratefully acknowledged. We also want to thank Arkema for supplying the copolymers used in this research.

\section{Appendix A. Supplementary data}

Supplementary data related to this article can be found at https:// doi.org/10.1016/j.polymer.2018.08.022.

\section{References}

[1] B. Notario, J. Pinto, M.A. Rodriguez-Perez, Nanoporous polymeric materials : a new class of materials with enhanced properties, Prog. Polym. Sci. 78-79 (2016) 93-139, https://doi.org/10.1016/j.pmatsci.2016.02.002.

[2] B. Notario, J. Pinto, E. Solorzano, J.A. de Saja, M. Dumon, M.A. Rodriguez-Perez, Experimental validation of the Knudsen effect in nanocellular polymeric foams, Polymer (Guildf) 56 (2015) 57-67, https://doi.org/10.1016/j.polymer.2014.10. 006.

[3] B. Notario, J. Pinto, M.A. Rodríguez-Perez, Towards a new generation of polymeric foams: PMMA nanocellular foams with enhanced physical properties, Polymer (Guildf) 63 (2015) 116-126, https://doi.org/10.1016/j.polymer.2015.03.003.

[4] B. Notario, A. Ballesteros, J. Pinto, M.A. Rodriguez-Perez, Nanoporous PMMA : a novel system with different acoustic properties, Mater. Lett. 168 (2016) 76-79, https://doi.org/10.1016/j.matlet.2016.01.037.

[5] S. Costeux, CO2-blown nanocellular foams, J. Appl. Polym. Sci. 131 (2014), https:// doi.org/10.1002/app.41293 41293(1)-41293(16).

[6] J. Pinto, B. Notario, R. Verdejo, M. Dumon, S. Costeux, M.A. Rodriguez-Perez, Molecular confinement of solid and gaseous phases of self-standing bulk nanoporous polymers inducing enhanced and unexpected physical properties, Polymer (Guildf) 113 (2017) 27-33, https://doi.org/10.1016/j.polymer.2017.02.046.

[7] J. Martin de-Leon, V. Bernardo, M.A. Rodriguez-Perez, Low density nanocellular polymers based on PMMA produced by gas dissolution Foaming : fabrication and cellular structure characterization, Polymers (Basel) 8 (2016) 1-16, https://doi. org/10.3390/polym8070265.

[8] S. Perez-Tamarit, B. Notario, E. Solorzano, M.A. Rodriguez-Perez, Light transmission in nanocellular polymers: are semi-transparent cellular polymers possible? Mater. Lett. 210 (2018) 39-41, https://doi.org/10.1016/j.matlet.2017.08.109. 
[9] L. Li, L. Schulte, L.D. Clausen, K.M. Hansen, G.E. Jonsson, S. Ndoni, Gyroid nanoporous membranes with tunable permeability, ACS Nano 5 (2011) 7754-7766, https://doi.org/10.1021/nn200610r.

[10] J. Pinto, M. Dumon, M.A. Rodriguez-Perez, R. Garcia, C. Dietz, Block copolymers self-assembly allows obtaining tunable micro or nanoporous membranes or depth filters based on PMMA; fabrication method and nanostructures, J. Phys. Chem. C 118 (2014) 4656-4663, https://doi.org/10.1021/jp409803u.

[11] G.Q. Lu, X.S. Zhao, Nanoporous materials - an overview, Nanoporous Mater. Sci. Eng. Imperial College Press, London, 2004, , https://doi.org/10.1142/ 9781860946561_0001.

[12] H.P. Hentze, M. Antonietti, Porous polymers and resins for biotechnological and biomedical applications, Rev. Mol. Biotechnol. 90 (2002) 27-53, https://doi.org/ 10.1016/S1389-0352(01)00046-0.

[13] D.A. Bernards, T.A. Desai, Nanoscale porosity in polymer films: fabrication and therapeutic applications, Soft Matter 6 (2010) 1621-1631, https://doi.org/10. 1039/B922303G.

[14] J. Martin-de Leon, V. Bernardo, M.A. Rodriguez-Perez, Key production parameters to obtain transparent nanocellular PMMA, Macromol. Mater. Eng. (2017), https:// doi.org/10.1002/mame.201700343 1700343(1)-1700343(5)..

[15] H. Guo, A. Nicolae, V. Kumar, Solid-state poly(methyl methacrylate) (PMMA) nanofoams. Part II: low-temperature solid-state process space using $\mathrm{CO} 2$ and the resulting morphologies, Polymer (Guildf). 70 (2015) 231-241, https://doi.org/10. 1016/j.polymer.2015.06.031.

[16] H. Guo, V. Kumar, Solid-state poly(methyl methacrylate) (PMMA) nanofoams. Part I: low-temperature $\mathrm{CO} 2$ sorption, diffusion, and the depression in PMMA glass transition, Polymer (Guildf) 57 (2015) 157-163, https://doi.org/10.1016/j. polymer.2014.12.029.

[17] H. Guo, V. Kumar, Some thermodynamic and kinetic low-temperature properties of the PC-CO2 system and morphological characteristics of solid-state PC nanofoams produced with liquid CO2, Polymer (Guildf) 56 (2015) 46-56, https://doi.org/10. 1016/j.polymer.2014.09.061.

[18] H. Guo, A. Nicolae, V. Kumar, Solid-State microcellular and nanocellular polysulfone foams, J. Polym. Sci., Part B: Polym. Phys. 53 (2015) 975-985, https://doi. org/10.1002/polb.23719.

[19] V. Bernardo, J. Martín-de Leon, M.A. Rodriguez-Perez, Production and characterization of nanocellular polyphenylsulfone foams, Mater. Lett. 178 (2016) 155-158, https://doi.org/10.1016/j.matlet.2016.05.002.

[20] H. Guo, A. Nicolae, V. Kumar, Fabrication of high temperature polyphenylsulfone nanofoams using high pressure liquid carbon dioxide, Cell. Polym. 35 (2015) 2016.

[21] D. Miller, P. Chatchaisucha, V. Kumar, Microcellular and nanocellular solid-state polyetherimide (PEI) foams using sub-critical carbon dioxide I. Processing and structure, Polymer (Guildf) 50 (2009) 5576-5584, https://doi.org/10.1016/j. polymer.2009.09.020.

[22] D. Miller, V. Kumar, Microcellular and nanocellular solid-state polyetherimide ( PEI ) foams using sub-critical carbon dioxide II. Tensile and impact properties, Polymer (Guildf) 52 (2011) 2910-2919, https://doi.org/10.1016/j.polymer.2011.04.049.

[23] C. Zhou, N. Vaccaro, S.S. Sundarram, W. Li, Fabrication and characterization of polyetherimide nanofoams using supercritical CO 2, J. Cell. Plast. 48 (2012) 239-255, https://doi.org/10.1177/0021955X12437984.

[24] V.I. Kalikmanov, Nucleation Theory, Springer, 2013.

[25] S. Costeux, L. Zhu, Low density thermoplastic nanofoams nucleated by nanoparticles, Polymer (Guildf) 54 (2013) 2785-2795, https://doi.org/10.1016/j. polymer.2013.03.052.

[26] V. Bernardo, J. Martin-de León, E. Laguna-Gutiérrez, M.Á. Rodríguez-Pérez, PMMAsepiolite nanocomposites as new promising materials for the production of nanocellular polymers, Eur. Polym. J. 96 (2017) 10-26, https://doi.org/10.1016/j. eurpolymj.2017.09.002.

[27] J. Pinto, D. Morselli, V. Bernardo, B. Notario, D. Fragouli, M.A. Rodriguez-Perez, A. Athanassiou, Nanoporous PMMA foams with templated pore size obtained by localized in situ synthesis of nanoparticles and CO 2 foaming, Polymer (Guildf) 124 (2017) 176-185, https://doi.org/10.1016/j.polymer.2017.07.067.

[28] C. Forest, P. Chaumont, P. Cassagnau, B. Swoboda, P. Sonntag, CO2 nano-foaming of nanostructured PMMA, Polymer (Guildf). 58 (2015) 76-87, https://doi.org/10. 1016/j.polymer.2014.12.048.

[29] J. Pinto, M. Dumon, M. Pedros, J. Reglero, M.A. Rodriguez-Perez, Nanocellular CO2 foaming of PMMA assisted by block copolymer nanostructuration, Chem. Eng. J. 243 (2014) 428-435, https://doi.org/10.1016/j.cej.2014.01.021.
[30] J. Pinto, J.A. Reglero-ruiz, M. Dumon, M.A. Rodriguez-Perez, Temperature influence and $\mathrm{CO} 2$ transport in foaming processes of poly (methyl methacrylate)- block copolymer nanocellular and microcellular foams, J. Supercrit. Fluids 94 (2014) 198-205, https://doi.org/10.1016/j.supflu.2014.07.021.

[31] P. Spitael, C.W. Macosko, R.B. Mcclurg, Block copolymer micelles for nucleation of microcellular thermoplastic foams, Macromolecules 37 (2004) 6874-6882.

[32] H. Yokoyama, K. Sugiyama, Nanocellular structures in block copolymers with CO2philic blocks using $\mathrm{CO} 2$ as a blowing agent: crossover from micro- to nanocellular structures with depressurization temperature, Macromolecules 38 (2005) 10516-10522, https://doi.org/10.1021/ma051757j.

[33] H. Yokoyama, L. Li, C. Dutriez, Y. Iwakura, K. Sugiyama, H. Masunaga, S. Sasaki, H. Okuda, Horizontally and vertically aligned polymeric Nanosheets: CO 2 -induced morphological changes of block copolymer thin films, Macromolecules 41 (2008) 8626-8631.

[34] J.A. Reglero Ruiz, M. Dumon, J. Pinto, M.A. Rodriguez-Perez, Low-density nanocellular foams produced by high-pressure carbon dioxide, Macromol. Mater. Eng. 296 (2011) 752-759, https://doi.org/10.1002/mame.201000346.

[35] C. Forest, P. Chaumont, P. Cassagnau, B. Swoboda, P. Sonntag, Nanofoaming of PMMA using a batch CO2 process: influence of the PMMA viscoelastic behaviour, Polymer (Guildf) 77 (2015) 1-9, https://doi.org/10.1016/j.polymer.2015.09.011.

[36] P. Gerard, L. Couvreur, S. Magnet, Controlled architecture polymers at Arkema: synthesis, morphology and properties of all- acrylic block copolymers, ACS Symp. Ser. vol. 1024, 2009, pp. 361-373.

[37] L. Lalande, Structure et mécanismes de microdéformation de polyméthylméthacrylates renforcés au choc, École Polytechnique Fédérale De Lausanne, 2007.

[38] P. Ge, L. Lalande, C.J.G. Plummer, J.E. Ma, The influence of matrix modification on fracture mechanisms in rubber toughened polymethylmethacrylate, Polymer (Guildf) 47 (2006) 2389-2401, https://doi.org/10.1016/j.polymer.2006.02.016.

[39] L. Lalande, C.J.G. Plummer, P. Ge, J.E. Ma, Microdeformation mechanisms in rubber toughened PMMA and PMMA-based copolymers, Eng. Fract. Mech. 73 (2006) 2413-2426, https://doi.org/10.1016/j.engfracmech.2006.05.014.

[40] V. Kumar, N.P. Suh, A process for making microcellular parts, Polym. Eng. Sci. 30 (1990) 1323-1329.

[41] M.D. Abràmoff, P.J. Magalhães, S.J. Ram, Image processing with ImageJ, Biophot. Int. 11 (2004) 36.

[42] J. Pinto, E. Solorzano, M.A. Rodriguez-perez, J.A. De Saja, Characterization of the cellular structure based on user-interactive image analysis procedures, J. Cell. Plast. 49 (2013) 555-575, https://doi.org/10.1177/0021955X13503847.

[43] V. Kumar, Process Synthesis for Manufacturing Microcellular Thermoplastic Parts, Massachusetts Institute of Technology, 1988.

[44] S. Wu, formation of dispersed phase in incompatible polymer interfacial and rheological effects, Polym. Eng. Sci. 27 (1987) 335-343.

[45] M.D. Whitmore, T.W. Smith, Swelling of copolymer micelles by added homopolymer, Macromolecules 27 (1994) 4673-4683, https://doi.org/10.1021/ ma00095a006.

[46] T. Imae, H. Tabuchi, K. Funayama, A. Sato, Self-assemblies of block copolymer of 2perfluorooctylethyl methacrylate and methyl methacrylate, Colloids Surf., A 167 (2000) 73-81.

[47] N.A. Memon, Rheological properties and the interface in polycarbonate/impact modifier blends: effect of modifier shell molecular weight, J. Polym. Sci. B Polym. Phys. 36 (1998) 1095-1105, https://doi.org/10.1002/(sici)1099-0488(199805) 36:7<1095::aid-polb1 > 3.3.co;2-n.

[48] P. Bardollet, M. Bousmina, R. Muller, Relationship between structure and rheological properties in the melt of polymers containing spherical inclusions, Polym. Adv. Met. Technol. 6 (1995) 301-308, https://doi.org/10.1002/pat.1995. 220060508.

[49] F. Rindfleisch, T.P. DiNoia, M. a. McHugh, Solubility of polymers and copolymers in supercritical CO2, J. Phys. Chem. Chem. 100 (1996) 15581-15587, https://doi.org/ 10.1021/jp9615823.

[50] J. Kumaki, Observation of polymer chain structures in two-dimensional fi lms by atomic force microscopy, Polym. J. 48 (2015) 3-14, https://doi.org/10.1038/pj. 2015.67.

[51] D.Q. Zou, H. Yoshida, Size effect of silica nanoparticles on thermal decomposition of PMMA, J. Ann. Therm. Anal. Calorim. 99 (2010) 21-26, https://doi.org/10. 1007/s10973-009-0531-4. 